\title{
Site fidelity and seasonal movement patterns of adult California sheephead Semicossyphus pulcher (Labridae): an acoustic monitoring study
}

\author{
Darin T. Topping ${ }^{1, *}$, Christopher G. Lowe ${ }^{1}$, Jennifer E. Caselle ${ }^{2}$ \\ ${ }^{1}$ Department of Biological Sciences, California State University Long Beach, 1250 Bellflower Boulevard, Long Beach, \\ California 90840-3702, USA \\ ${ }^{2}$ Marine Science Institute, University of California Santa Barbara, Santa Barbara, California 93106, USA
}

\begin{abstract}
The California sheephead Semicossyphus pulcher Ayres (Labridae) is a temperate, rocky-reef/kelp-bed fish that is sought by recreational and commercial fishermen. Long-term acoustic monitoring was used to ascertain site fidelity and seasonal movement patterns of $S$. pulcher. We implanted 16 adult ( 24 to $36 \mathrm{~cm}$ standard length) fish with long-term ( 1 yr) acoustic transmitters and their presence and movement patterns were monitored in the Catalina Marine Science Center Marine Life Reserve using an acoustic receiver array. A method was developed that explained some of the variability in detection frequencies. A negative relationship between detection frequency and activity (rate of movement) was found for $S$. pulcher moving within the array. Most fish exhibited high site fidelity to the general area of the reserve, with 13 of the 16 fish detected spending an average of $99 \pm 2 \%$ of their total days at liberty in the study area, with a mean of $90 \pm 9 \%$ of total residence time spent within a $600 \mathrm{~m}$ core area. However, these fish showed some variability in area use between months, exhibiting periods of expansion in their range. Fish also tended to increase activity as seasonal water temperature increased. These expanded movements resulted in some fish crossing the reserve boundary for extended periods or leaving the reserve permanently.
\end{abstract}

KEY WORDS: Seasonal movements · Activity · Temperature • Marine reserve · Site fidelity · Residency · Acoustic telemetry · California sheephead

\section{INTRODUCTION}

The California sheephead Semicossyphus pulcher Ayres (Labridae) is a carnivorous, diurnal, temperate, rocky-reef/kelp-bed fish that is highly sought in recreational and commercial fisheries in California, USA, and Mexico (Cowen 1986, Hobson \& Chess 1986, Stephens 2002, Topping et al. 2005). The commercial fishery for $S$. pulcher is primarily made up of the premium live-finfish fishery (PLFF), which uses traps to target smaller, 'plate-size' females in order to sell them live in restaurants and markets (Stephens 2002). In contrast, the recreational fishery generally targets the larger size classes which, for this protogynous hermaphroditic species, tend to be male.
Current recreational regulations are based on bag limits and minimum size restrictions, while the PLFF is regulated by size restrictions and regional quotas (California Department of Fish \& Game Regulations). Because Semicossyphus pulcher is a protogynous hermaphrodite, both environmental and social factors can affect their size at sex change and population sex ratio (Warner 1975, Cowen 1990), thereby making it difficult to predict the extent to which size and bag limits affect reproductive output. For this and other reasons, managers have looked toward marine protected areas (MPAs) to increase abundances and sizes of fished species within these reserves, while possibly providing a source stock for outside areas (e.g. Johnson et al. 1999, McClanahan \& Mangi 2000, Roberts et al. 2001). 
While measuring the effectiveness of an MPA for protecting any particular species is a complex undertaking, at a minimum, we must understand the extent to which individuals remain inside the boundaries of these areas while maintaining their normal activities, including foraging, refuging, and reproduction (Barrows 1996, Kramer \& Chapman 1999, Meyer et al. 2001, Lowe et al. 2003, Topping et al. 2005). Thus, it is essential to determine home range size and the fidelity to home ranges over varying temporal scales. This information is not only critical for evaluating existing MPAs, but also for determining the optimal size and location of new reserves, and may be particularly important for reef- and kelp-bed associated species such as Semicossyphus pulcher.

Although relatively little is known about home range sizes and the degree of site fidelity of many nearshore gamefishes in the eastern Pacific, a few studies have described short-term fidelity and habitat use for certain nearshore species of gamefishes, including Semicossyphus pulcher. In a study by Topping et al. (2005), using manual acoustic tracking techniques, $S$. pulcher were found to occupy relatively small home ranges (938 to $82000 \mathrm{~m}^{2}$ ) and generally use the same nighttime resting location over multiple $24 \mathrm{~h}$ periods that the fish were tracked (for periods from 1 to $6 \mathrm{~d}$ ). S. pulcher were found to follow the reef contours and tended to avoid crossing deep sandy areas adjacent to steeply sloping reef contours. In addition, Johnson et al. (1994) utilized tag and recapture techniques for $S$. pulcher on an artificial reef and had a remarkably high recapture rate $(70 \%)$ after a 7 mo period. Although both these studies indicate that $S$. pulcher may have a high degree of site fidelity to home ranges over short periods of time, it is not known whether they exhibit seasonal shifts in home ranges or movement patterns. The present study sought to address these issues.

One factor that may affect a fish's seasonal area use or site fidelity is its reproductive strategy or behavior (Coleman et al. 1996, Sheaves et al. 1999, Bolden 2000). Although it is unclear whether Semicossyphus pulcher consistently maintain territories similar to other labrids, it has been observed that males become increasingly territorial throughout the day during periods of spawning activity (Adreani et al. 2004). Since spawning activity occurs around sunset, fish may only show differences in space utilization for short periods (e.g. late afternoon) on particular days during the spawning season (June to September). Because of this behavior it is possible that larger-scale movement patterns differ between the reproductive and nonreproductive seasons, when sequestering energy for gonadal development, or while fish are setting up spawning territories (Warner 1975, Adreani et al. 2004). Potential shifts in home range or expansion of home ranges during breeding seasons may cause fish protected within MPAs to cross reserve boundaries more often during those periods, potentially making them more susceptible to fishing-related mortality.

In this study, we used long-term ( 1 yr) acoustic telemetry monitoring to determine the seasonal movement patterns and site fidelity of adult Semicossyphus pulcher in a marine reserve at Santa Catalina Island (Catalina Marine Science Center Marine Life Reserve, CMLR), California, USA. We compare these longerterm, less spatially resolved movements with shortterm, fine-scale movements observed previously for this species at the same location (Topping et al. 2005).

\section{MATERIALS AND METHODS}

Study site. This study was conducted at Catalina Marine Science Center Marine Life Reserve (CMLR), on the leeward side of Santa Catalina Island, California, USA ( $33^{\circ} 26^{\prime} \mathrm{N}, 118^{\circ} 29^{\prime} \mathrm{W}$ ) (Fig. 1), a no-take marine reserve since 1988, encompassing $130000 \mathrm{~m}^{2}$. Marine habitat types in the CMLR include kelp beds, rocky reefs, and mud/sand. High-resolution benthic habitat maps describing these habitats can be found in Lowe et al. (2003) and Topping et al. (2005). The CMLR also contains anthropogenic habitats, such as a boulder riprap, a pier, a floating dock, and mooring blocks. There are 2 distinct areas of the reserve: 'Cove', a large sandy cove $(250 \times 300 \mathrm{~m})$; and 'Outside Wall', a long, narrow, stretch of rock reef (600 $\mathrm{m}$ ) bordering the coastline. The sandy cove is bordered on 2 sides by steep rocky reefs and a rock rubble beach opposite the mouth of the cove; depths in the cove range from 0 to $40 \mathrm{~m}$. The narrow, contiguous reef is generally made up of steeply sloping rock walls and rocky rubble; this reef extends approximately 50 to $80 \mathrm{~m}$ out from the land, sloping quickly to a depth of $50 \mathrm{~m}$, where it meets a sand/mud substratum (Fig. 1).

Fish tagging. We caught 16 Semicossyphus pulcher using hook and line at various locations within the CMLR and quickly anesthetized them to Level 4 (total loss of equilibrium) with MS-222 (Finquel $^{\mathrm{TM}}$, conc. $0.15 \mathrm{~g} \mathrm{l}^{-1}$ ) (Summerfelt \& Smith 1990). A $1 \mathrm{~cm}$ incision was made $1 \mathrm{~cm}$ off-center from the ventral midline between the pelvic fins and the anus, and a small acoustic transmitter was placed within the visceral cavity. The incision was closed with 2 to 3 surgical sutures (Ethicon Chromic Gut 2-0) and the fish were transferred to a tub of seawater for recovery. The time from initial capture to release ranged from 6 to $15 \mathrm{~min}$. During recovery, each fish was measured (standard length, SL) and then tagged externally in the dorsal musculature with a spaghetti dart tag for visual identification. The sex of each fish was visually determined using color pattern and morphology (Warner 1975). 
Fig. 1. Shaded-relief bathymetry map of Catalina Marine Science Center Marine Life Reserve (Santa Catalina Island, California, USA) including an overlay of monitor locations with estimated $150 \mathrm{~m}$ radius detection zones in 2 areas of reserve, a sandy cove (Cove) and a narrow contiguous stretch of rock reef (Outside Wall). $\mathrm{P}=$ Pier, EW $=$ East Wall, $\mathrm{CC}=$ Chalk Cliffs, IP = Intake Pipes, 3C = 3 Caves, Pump = Pumpernickel

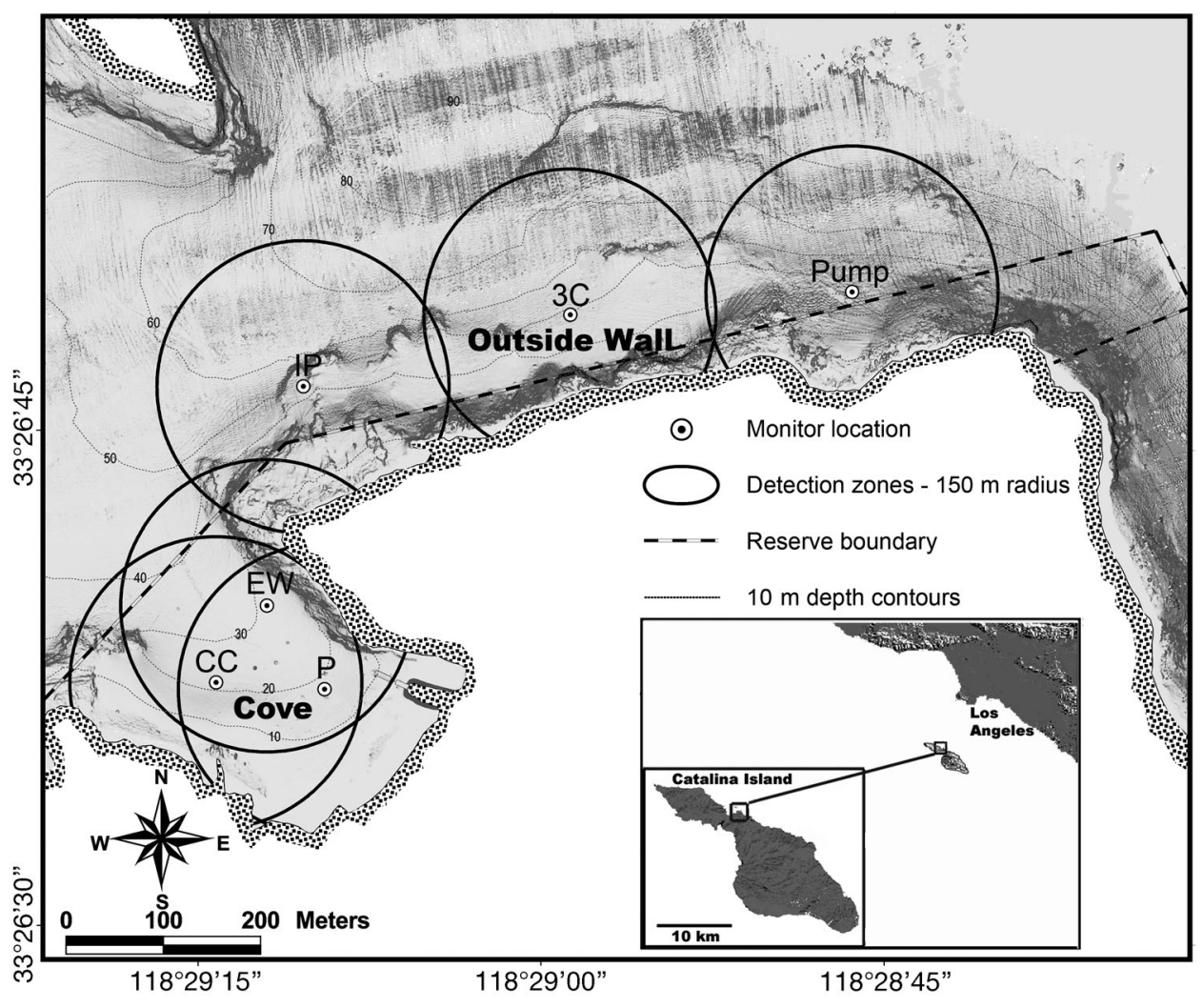

Acoustic monitoring. Fish were fitted with individually coded transmitters (Vemco V8-2L-R256 Rcode, $8 \mathrm{~mm}$ diameter $\times 30 \mathrm{~mm}$ length, or V8SC-1L-R256 Rcode, $8 \mathrm{~mm}$ diameter $\times 24 \mathrm{~mm}$ length) and the movement patterns of these fish in the reserve were monitored using 6 automated passive acoustic receivers (Vemco Model VR1). As a fish swims through the detection zones, the monitors detect the individually specific transmitter code and record the date and time of detection. Vemco V8-2L-R256 Rcode transmitters were used for the first 3 fish, before switching transmitter type to Vemco V8SC-1L-R256 for the remaining 13 fish. The latter tags increased the nominal battery life from approximately 100 to approximately $347 \mathrm{~d}$. The V8-2L-R256 transmitters emitted a specific acoustic $(69.0 \mathrm{kHz})$ pulse train at random intervals every 30 to $90 \mathrm{~s}$, while the pulse period for the V8SC-1L-R256 transmitters was 40 to $120 \mathrm{~s}$.

Range tests were conducted prior to tagging and permanent receiver deployment to determine the receiver's detection range of the acoustic transmitters used in the study (Simpfendorfer et al. 2002, Szedlmayer \& Schroepfer 2005). This general range test was conducted by increasing the distance in $15 \mathrm{~m}$ increments between the receiver's hydrophone and the transmitter (V8SC-1L-R256). Transmitters were held in each position for a 30 min period until reaching the distance where pulses were no longer detected. This maximum detection range had an approximately $150 \mathrm{~m}$ radius; however, detection range varies with sea state, depth, submerged structure (i.e. rocks and kelp) and turbidity (Starr et al. 2000, 2002 Arendt et al. 2001b).

An acoustic monitor was placed in each of 6 locations distributed throughout the reserve (P: Pier, EW: East Wall, CC: Chalk Cliffs, IP: Intake Pipes, 3C: 3 Caves, Pump: Pumpernickel), such that there was overlap of estimated detection zones, providing near-complete coverage of the reserve (Fig. 1). In the Cove, the 3 monitors ( $\mathrm{P}, \mathrm{EW}, \mathrm{CC})$ were positioned to cover the entire cove, resulting in a large overlap of detection range, while the detection ranges of the 3 monitors along the Outside Wall (IP, 3C, Pump, placed $300 \mathrm{~m}$ apart) were slightly overlapping. Since Semicossyphus pulcher are benthic feeders, spending most of their time near the bottom, acoustic monitors were secured in midwater ( $10 \mathrm{~m}$ from the surface on buoy lines) with the hydrophone side pointing down to facilitate detection of fish on or near the bottom; however, bottom depths varied at the monitor locations (Fig. 1). Temperature data loggers (StowAway ${ }^{\circledR}$ TidbiT $^{\circledR}$ ) were deployed on the EW monitor mooring line, a central location to the monitoring array, at depths of 8,15 , and $25 \mathrm{~m}$, and were set to record once per hour. Mean daily water column temperature was calculated from the mean temperature across these depths. 
Detection frequency validation. Static range testing has shown that while the detection frequency (rate) of a given transmitter decreases with increasing distance from an acoustic monitor, the decrease may be linear (Simpfendorfer et al. 2002) or logistic (Szedlmayer \& Schroepfer 2005). To help us better gauge the detection frequency of fish fitted with coded transmitters moving within the acoustic receiver array, we double-tagged a Semicossyphus pulcher with both a V8SC-1L-R256 coded transmitter and a V8SC-1L standard pinger transmitter. This allowed us to manually track the fish, while simultaneously monitoring it with the acoustic receivers, thereby providing actual detection frequencies of a fish moving within the array. This fish was tracked over 4 separate $24 \mathrm{~h}$ periods (for details on manual tracking of S. pulcher see Topping et al. 2005). Tracking provided actual positions of the fish relative to the monitor array (mean distance from monitor $\mathrm{h}^{-1}$ ), as well as its rate of movement $\left(\mathrm{m} \mathrm{h}^{-1}\right)$ and habitat use data, which then was regressed with mean hourly detection frequencies over the same days this fish was tracked. To account for an inherent random pulse period (40 to $120 \mathrm{~s}$ ) associated with the Rcode transmitters, we averaged hourly distance and hourly detection frequency calculations over a $10 \mathrm{~h}$ period. This was an optimal time period for examining daily variation in number of detections. Spatial analyses were performed with ArcView GIS 3.2 software in conjunction with the 'Animal Movements Extension' (Hooge et al. 1999, 2001).

Data analysis. To estimate the degree of site fidelity of Semicossyphus pulcher in the CMLR (percentage of days detected in the reserve), the total number of days a fish was detected was divided by the total number of days between the date of release and the last date that each fish was detected by any monitor (i.e. days at liberty) or until the end of the study (347 d). Since there was near-complete monitor coverage of the reserve, it was assumed that on any date a fish was not detected at least once, it had moved out of the reserve. However, the detection range of some monitors extended beyond the reserve boundary, so even a detected fish might be outside the boundary at these locations. However, based on fine-scale tracking of $S$. pulcher in the CMLR by Topping et al. (2005), fish detected within the monitor area have a high probability of being within the habitat found inside the reserve area, rather than the deep sandy area outside the boundary. The total number of detections on each monitor for each fish during each month was used to determine relative monthly (and seasonal) fidelity to sites over the 11 to 12 mo battery life of the coded transmitters. In addition, to estimate the range of movement for each fish, we took the number of monitors by which a fish was detected each month and averaged it over the year to determine the yearly mean for a fish. This yearly mean for each fish was then subtracted from the number of monitors by which each fish was detected each month. After monthly deviations had been calculated for each fish, they were averaged by month across all fish. A deviation from the mean would signify an expansion (positive) or a contraction (negative) of their normal range (i.e. visiting more or fewer monitors). To test for differences between months we used a general linear model (GLM) using sequential sums of squares with mixed components to take into consideration repeated sampling of the same individuals across months. Tukey's pair-wise comparisons were used to compare between months. In addition, detection plots were used to illustrate when fish were present or absent from each monitor during the course of a year.

In order to explore potential causative factors of variance in the daily number of detections of each Semicossyphus pulcher over the year $(\approx$ seasonal movement and/or fidelity), the total number of daily detections at a fish's core monitor (i.e. the monitor that detected the fish the greatest number of times) was regressed with mean daily water column temperature (mean ${ }^{\circ} \mathrm{C}$ from 8,15 , and $25 \mathrm{~m}$ ) and daylight length. Since detections were reduced at night, when fish entered rocky crevices to refuge (see 'Results; Detection frequency validation'), mean daily detections were standardized by daylight length to remove the influence of this behavior on the analyses. The standardizing procedure used the residuals of regressions between daily detections and daylight length in regression analyses with daily water column temperature (Atchley et al. 1976, Jakob et al. 1996). In order to acquire a representative example of actual mean daily detection frequencies, we added 180 to these residuals, which resulted in positive values reflecting near-actual daily detection frequencies on graphs.

\section{RESULTS}

We acoustically monitored 16 adult $(24.5$ to $35.5 \mathrm{~cm}$ $\mathrm{SL})$ Semicossyphus pulcher from June to November $2000(\mathrm{n}=3)$ and from June 2001 to April $2003(\mathrm{n}=13)$ (Table 1). The 8 males ( 26.0 to $35.5 \mathrm{~cm} \mathrm{SL}$ ) were significantly larger in size (Student's $t=1.96, \mathrm{p}=0.035$ ) than the 8 females ( 24.5 to $32.5 \mathrm{~cm} \mathrm{SL}$ ), and all fish were within a size range that was representative of the 'legal-sized' adult reserve population.

\section{Detection frequency validation}

An additional $35 \mathrm{~cm}$ SL male Semicossyphus pulcher concurrently tracked and monitored over four $24 \mathrm{~h}$ periods $(12,25,26$ October 2002, and 8 January 2003) 
Table 1. Semicossyphus pulcher. Percentage of days at liberty that fish were detected at 6 locations throughout Catalina Marine Science Center Marine Life Reserve, based on days at liberty during nominal transmitter life (347 d). Fish were detected at more than one location on a given day; those that had large home ranges or were in areas of monitor overlap have total percentages over 100. SL $=$ standard length; Time at liberty $=$ number of days between date of release and last detection of fish by a monitor; $\mathrm{P}=$ Pier, EW $=$ East Wall, $\mathrm{CC}=$ Chalk Cliffs, IP $=$ Intake Pipes, $3 \mathrm{C}=3$ Caves, Pump $=$ Pumpernickel ${ }_{i}$ Max. range $=$ estimate of greatest distance measured across all contiguous monitor zones that detected relevant fish, and does not include areas outside array; nd = monitor not deployed at time of study

\begin{tabular}{|c|c|c|c|c|c|c|c|c|c|c|c|c|}
\hline \multirow{2}{*}{$\begin{array}{l}\text { Fish } \\
\text { No. }\end{array}$} & \multirow{2}{*}{$\begin{array}{l}\mathrm{SL} \\
(\mathrm{cm})\end{array}$} & \multirow[t]{2}{*}{ Sex } & \multirow{2}{*}{$\begin{array}{c}\text { Date released } \\
(\mathrm{mm} / \mathrm{dd} / \mathrm{yy})\end{array}$} & \multirow{2}{*}{$\begin{array}{l}\text { Location } \\
\text { released }\end{array}$} & \multirow{2}{*}{$\begin{array}{l}\text { Time at } \\
\text { liberty (d) }\end{array}$} & \multirow{2}{*}{$\mathrm{P}$} & \multirow{2}{*}{$\begin{array}{l}\text { Cove } \\
\text { EW }\end{array}$} & \multirow[b]{2}{*}{$\mathrm{CC}$} & \multicolumn{3}{|c|}{ — Outside Wall— } & \multirow{2}{*}{$\begin{array}{l}\text { Max. range } \\
\text { (m) }\end{array}$} \\
\hline & & & & & & & & & IP & $3 C$ & Pump & \\
\hline 1 & 30.8 & M & 06/08/00 & $\mathrm{P}$ & 161 & 100 & 100 & 100 & nd & nd & nd & 300 \\
\hline 2 & 30.8 & $\mathrm{~F}$ & 06/08/00 & $\mathrm{P}$ & 44 & 100 & 100 & 100 & nd & nd & nd & 300 \\
\hline 3 & 29.4 & M & 06/08/00 & $\mathrm{CC}$ & 65 & 100 & 100 & 100 & nd & nd & nd & 300 \\
\hline 4 & 33.0 & M & 07/08/01 & $\mathrm{CC}$ & 376 & 100 & 100 & 100 & 4.3 & 0.0 & 0.0 & 673 \\
\hline 5 & 26.0 & $\mathrm{M}$ & 07/08/01 & $\mathrm{CC}$ & 390 & 98.9 & 91.4 & 97.2 & 0.8 & 0.0 & 0.0 & 673 \\
\hline 6 & 24.5 & $\mathrm{~F}$ & 07/08/01 & $\mathrm{CC}$ & 825 & 57.0 & 53.3 & 48.7 & 54.7 & 26.8 & 0.0 & 860 \\
\hline 7 & 25.0 & $\mathrm{~F}$ & 07/09/01 & EW & 532 & 100 & 100 & 100 & 3.8 & 0.0 & 0.0 & 673 \\
\hline 8 & 32.0 & $\mathrm{M}$ & 07/10/01 & $\mathrm{P}$ & 533 & 100 & 100 & 100 & 16.2 & 1.2 & 0.5 & 1241 \\
\hline 9 & 34.0 & $\mathrm{M}$ & 08/12/01 & $3 \mathrm{C}$ & 213 & 0.0 & 0.0 & 0.0 & 99.1 & 100 & 1.9 & 860 \\
\hline 10 & 29.0 & $\mathrm{M}$ & 08/12/01 & $3 \mathrm{C}$ & 493 & 0.3 & 0.0 & 0.3 & 49.9 & 100 & 62.4 & 1241 \\
\hline 11 & 32.5 & $\mathrm{~F}$ & 08/12/01 & $3 \mathrm{C}$ & 329 & 0.6 & 0.9 & 0.9 & 18.8 & 81.2 & 52.0 & 1241 \\
\hline 12 & 29.0 & $\mathrm{~F}$ & 08/17/01 & IP & 322 & 2.5 & 1.2 & 4.7 & 100 & 82.0 & 0.3 & 1241 \\
\hline 13 & 30.0 & $\mathrm{~F}$ & 08/18/01 & Pump & 475 & 0.0 & 0.3 & 0.3 & 1.8 & 23.0 & 100 & 1159 \\
\hline 14 & 35.5 & $\mathrm{M}$ & 09/09/01 & IP & 650 & 3.0 & 4.9 & 9.7 & 100 & 91.6 & 0.8 & 1241 \\
\hline 15 & 27.0 & $\mathrm{~F}$ & $10 / 09 / 01$ & $\mathrm{P}$ & 307 & 100 & 99.1 & 99.0 & 10.7 & 1.3 & 1.3 & 1241 \\
\hline 16 & 28.0 & $\mathrm{~F}$ & 02/10/02 & $3 C$ & 413 & 1.2 & 0.3 & 0.3 & 1.4 & 21.3 & 0.9 & 1241 \\
\hline
\end{tabular}

showed typical diurnal behavior, roaming over sand and rock/kelp habitats during the day (home range $\sim 5000 \mathrm{~m}^{2}$ ) and returning to a rock rubble/boulder refuge area at night. Transmitter signals were consequently blocked when the fish entered into a rocky refuge, resulting in near-zero detection frequencies at night. During daylight hours, mean $( \pm \mathrm{SD})$ detections averaged $26 \pm 12 \mathrm{~h}^{-1}$, ranging from 6 to $46 \mathrm{~h}^{-1}$. Mean hourly detections declined linearly as the fish's mean distance away from the monitor increased between the observed mean hourly distances of 17 and $165 \mathrm{~m}$ (mean distance 67.1 \pm 43.9 ) (Fig. $2 ; \mathrm{r}^{2}=0.53, \mathrm{p}=0.011$ ). Detections were also negatively related to the fish's rate of movement (ROM), which ranged from 20 to $250 \mathrm{~m} \mathrm{~h}^{-1}$ (mean ROM $96.2 \pm 44.0 \mathrm{~m} \mathrm{~h}^{-1}$ ) (Fig. 2; $\mathrm{r}^{2}=$ $0.65, \mathrm{p}=0.003$ ). Mean distance away from the monitors was not significantly correlated with ROM (Pearson's $\mathrm{r}=0.44, \mathrm{p}=0.18$ ).

\section{Site fidelity}

Total days at liberty ranged from 44 to 825 ; however, Fish Nos. 1, 2, and 3 had transmitters that were considerably shorter in battery life than those of the remaining 13 fish, and thus were excluded from all further analyses (Table 1). In addition, 9 of the remaining transmitters lasted longer than the $347 \mathrm{~d}$ nominal battery life, and in 1 case, a fish was detected for up to $825 \mathrm{~d}$, with a mean detection time of $451 \pm$ $162 \mathrm{~d}$. However, due to the uncertainty of data past the nominal $347 \mathrm{~d}$ battery life, all analyses were limited to a maximum $347 \mathrm{~d}$ at liberty.

Most fish exhibited high site fidelity to the general area of the reserve, with 13 of the 16 fish averaging $99 \pm 2 \%$ of their total days at liberty within the detection area, with a mean of $90 \pm 9 \%$ of total residence time spent within a $600 \mathrm{~m}$ core area (Table 1). Chrono-

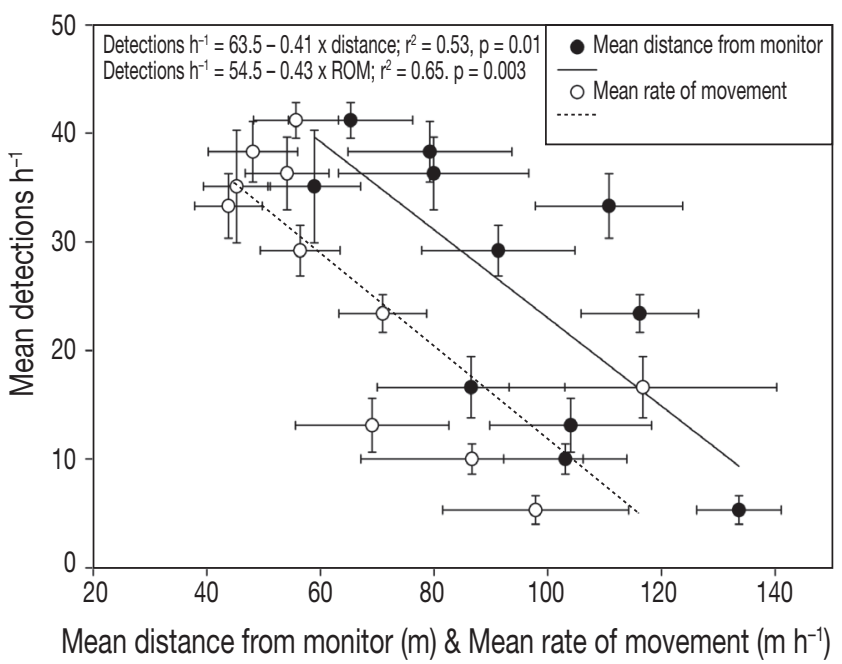

Fig. 2. Semicossyphus pulcher. Mean $( \pm \mathrm{SD})$ detection frequency validation of fish fitted with both an Rcode and a standard pinger-type transmitter. Mean hourly detections declined linearly as fish's mean distance $(\mathrm{m})$ away from the monitor increased. Mean hourly detections were also negatively related to fish's rate of movement (ROM) 


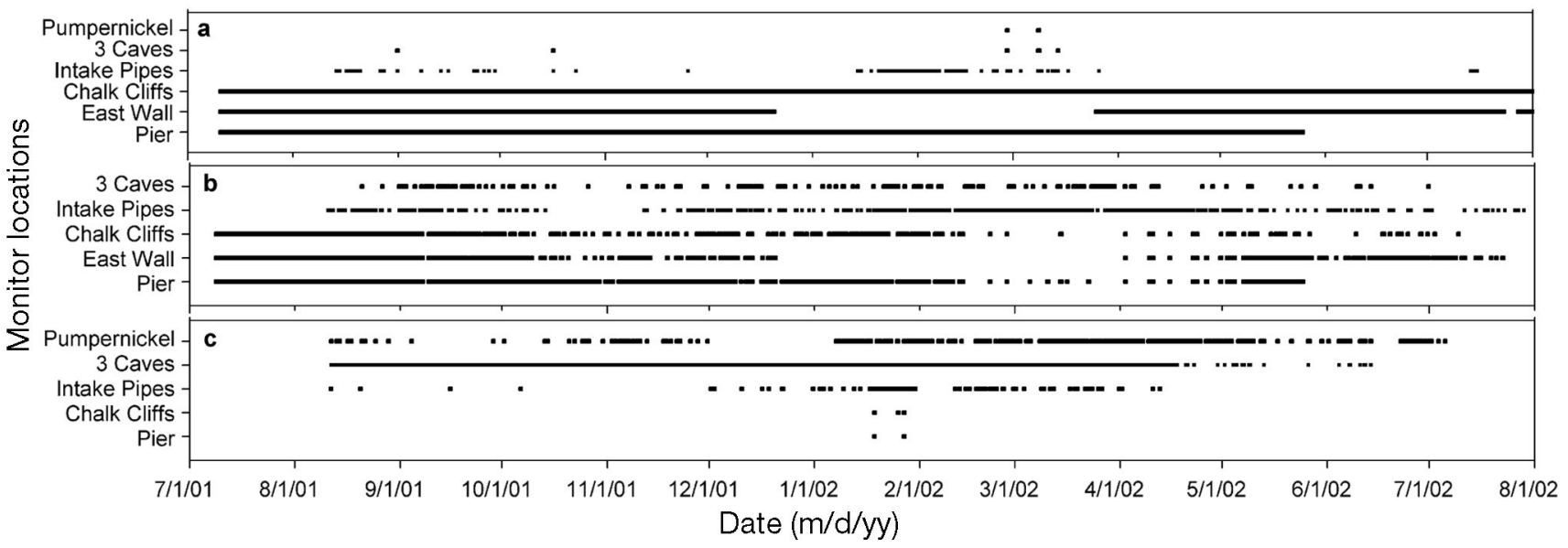

Fig. 3. Semicossyphus pulcher. Chronological detection plots for (a) Fish No. 8, (b) Fish No. 6 and (c) Fish No. 11. Plots are individual temporal records by each monitor showing presence ( $\bullet$ ) and absence (white gap). Visible gap between individual detections indicates period $>24 \mathrm{~h}$ during which fish was not detected

logical detections of Fish No. 8 by various monitors serves as a typical example of the pattern shown by the majority $(\mathrm{n}=13)$ of fish that exhibited high site fidelity to a general location, with detections mostly limited to 2-3 monitors ( 600 m), but occasionally detected by adjacent monitors during apparent range expansions at various times of the year (Fig. 3a).

Of the 16 fish monitored, 3 did not exhibit typical patterns of site fidelity. Like the majority of these fish, Fish No. 6 (24.5 cm SL female) was also detected during $100 \%$ of its days at liberty by at least 1 monitor; however, it used a larger daily activity space and exhibited a shift in core-area use. Fish No. 6 was frequently detected by 5 monitors on a single day, representing a linear distance of approximately $860 \mathrm{~m}$, but it also exhibited a switch from Cove area (P) to the Outside Wall (IP) area during various times of the year. This pattern is indicated by the even distribution of the percent days detected over multiple locations in the reserve (Table 1) and the chronology of detections (Fig. 3b). Since Semicossyphus pulcher are quiescent at night (Topping et al. 2005), if a fish was detected by a different non-overlapping monitor at night than on previous days, it was considered to have shifted its nighttime location. The switch in daytime location use by Fish No. 6 was concurrently followed by a shift in its nighttime location.

We detected 2 other fish (Nos. 11 and 16) on fewer days than expected. Time at liberty for Fish No. 11 was 329 d, but it exhibited a shift in its core area from $3 \mathrm{C}$ to
Pump during the last few months it was detected (Fig. 3c). During the last month, Fish No. 11 was not detected for a $10 \mathrm{~d}$ period, but returned to the Pump area for another week before complete detection loss, which might indicate a complete shift out of the reserve at the southeastern boundary. Interestingly, Fish No. 16, released on 10 February 2002 near the 3C monitor, was detected within the reserve for only 3 mo before leaving the detection area, but returned in April 2003, maintaining its residence within the same area for a further month before detection was again lost.



Fig. 4. Semicossyphus pulcher. Mean monthly deviations ( $( \pm \mathrm{SD})$ in number of monitors by which fish were detected, reflecting expansion (positive) or contraction (negative) of their normal range (gray bars). Letters above $x$-axis denote significant difference $(\mathrm{p}>0.05)$ between relevant months. Dashed curve: mean daily water column temperature. GLM: general linear model 


\section{Seasonal movement patterns}

Individuals showed seasonal variation in the location and size of area use, as indicated by the number of monitors by which they were detected each month. The number of monitors by which a fish was detected was used as a proxy for the range of movement of each fish. Because of the limited movement of fish and the difference in the spacing of the monitors between the Cove and Outside Wall (Fig. 1), fish released in the Cove were primarily detected by the 3 monitors placed in the Cove (detection range: 3 to 6 monitors), and fish along the Outside Wall were primarily detected by the 3 monitors along the Outside Wall (detection range: 2 to 6 monitors) (Table 1). However, most fish exhibited periodic expansions of this normal range, with a mean of $3.7 \pm 0.4$ monitors for fish tagged in the Cove and $2.8 \pm 0.6$ monitors for fish tagged along the Outside Wall.

The mean monthly deviations of the number of monitors by which fish were detected showed significant expansions (positive) or a contractions (negative) of their normal range (Fig. 4). There was a significant positive deviation in January 2002 (GLM; F = $2.74, \mathrm{p}=0.002$ ), and a greater than normal positive deviation during the entire period between December 2001 and March 2002, indicating range expansions during this period (Fig. 4). Some of the range expansions appeared to have occurred after anomalous water temperature increases. Of 13 fish, 10 expanded their range by the distance of at least 1 monitor $(\sim 300 \mathrm{~m})$ during the period from December to March, and at least 4 of these fish increased their overall range to slightly over $1 \mathrm{~km}$.

Since fish generally remained within a core area of approximately 300 to $600 \mathrm{~m}$, the monitor that detected a particular fish the greatest number of times was considered to be its core monitor. For Cove fish (n $=6$ ), the mean number of daily detections by the core monitor significantly decreased as mean daily water column temperature increased from 12.5 to $18.5^{\circ} \mathrm{C}$ (Fig. $5 \mathrm{a} ; \mathrm{r}^{2}=$ $0.38, \mathrm{p}<0.0001)$. For the Outside Wall fish ( $\mathrm{n}=6$; Fish No. 16 was not included in the analysis because of its long-term absence), the relationship between number of detections and water temperature was similar to that for Cove fish (Fig. 5b; $\mathrm{r}^{2}=0.15, \mathrm{p}<$ 0.0001). Seasonal mean daily detection frequencies of core monitors were analyzed by the following monthly groupings: pre-spawning (April to May), spawning (June to September), post-spawning (October to November), and winter (December to March). There was significant seasonal variation in mean daily detections among the core monitors of Cove fish, with the greatest number of detections during the April to May period (Fig. 6; ANOVA: $F=523.6$, $\mathrm{p}<0.001$ ). There was a more even seasonal distribution of daily detection on the Outside Wall monitors, with the periods October to November and December to March containing fewer detections than June to September and April to May (Fig. 6; ANOVA: $F=$ 106.4, $\mathrm{p}<0.001)$.

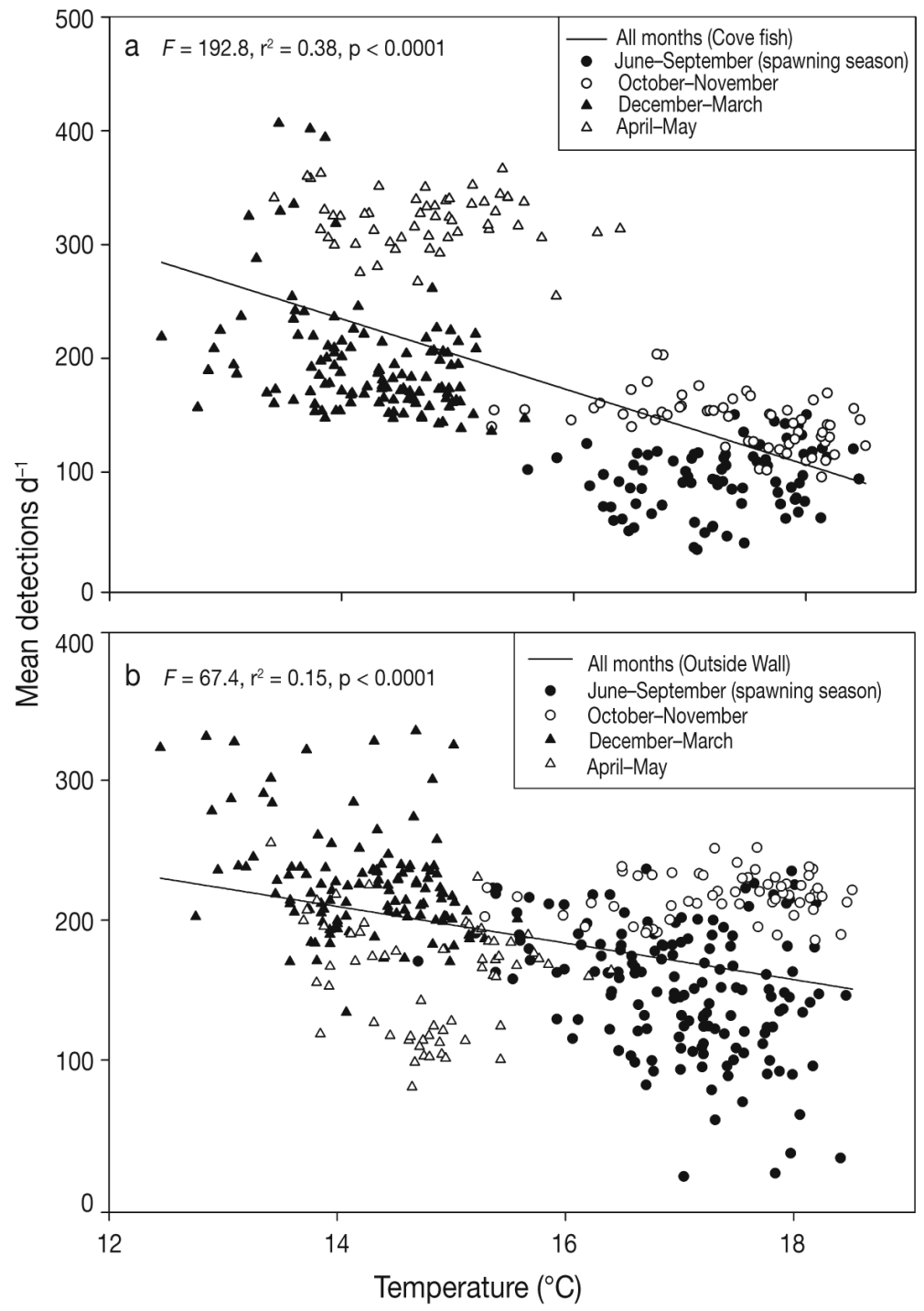

Fig. 5. Semicossyphus pulcher. Relationships between mean daily water column temperature and mean daily detections by core monitors of (a) Cove fish and (b) Outside Wall fish (core monitor = monitor with greatest number of detections of relevant fish, and indicates a high degree of residency near that monitor). Mean daily detection frequencies separated into monthly groupings of pre-spawning (April to May), spawning (June to September), postspawning (October to November), and winter (December to March) periods 


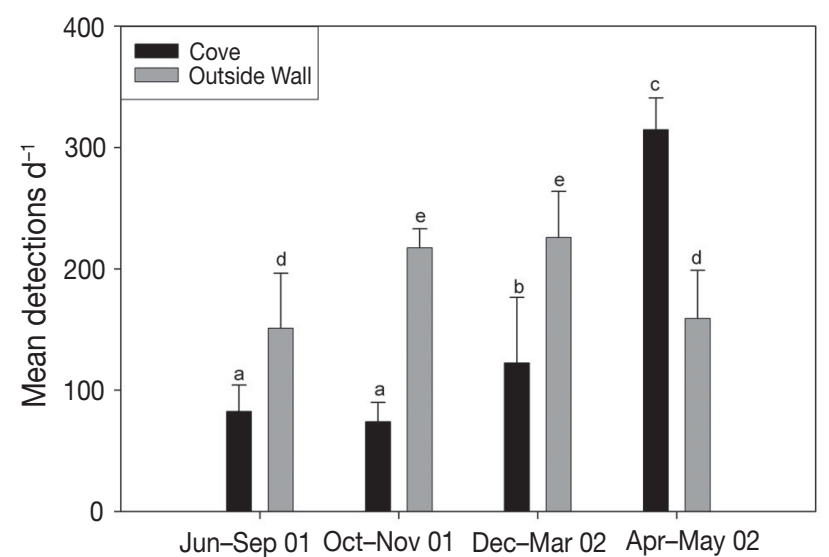

Fig. 6. Semicossyphus pulcher. Mean $(+\mathrm{SD})$ seasonal mean daily detections by core monitors of (a) Cove fish and (b) Outside Wall fish during pre-spawning (April to May), spawning (June to September), post-spawning (October to November), and winter (December to March) periods. Letters above bars indicate significantly different mean daily detection frequencies among Cove (ANOVA: $F=523.6, \mathrm{p}<0.001$ ) or Outside Wall (ANOVA: $F=106.4, \mathrm{p}<0.001$ ) fish

\section{DISCUSSION}

Long-term ( 1 yr) passive acoustic monitoring was used to ascertain the site fidelity and seasonal movement patterns of Semicossyphus pulcher. The advent of passive monitoring systems has improved upon traditional tag and recapture/resight methods in obtaining continuous presence/absence data for aquatic organisms. The ability to monitor multiple individuals concurrently for up to several years can provide important residency data. In addition, recent studies have begun to establish methods for validating and analyzing presence/absence detection data that expand the use of this monitoring equipment to better determine home ranges and activity patterns, with results becoming comparable to those obtained via laborious manual telemetry or via expensive high-resolution radio-acoustic positioning and telemetry (VRAP) methods (Bradbury et al. 1995, O'Dor et al. 2002, Simpfendorfer et al. 2002, Parsons et al. 2003, Heupel et al. 2004, 2006).

By using a 'test fish' fitted with both a continuous pinger (manual tracking) and an Rcode type transmitter (passive monitoring), we were able to correlate actual detection frequencies obtained in the field with fine-scale manual telemetry movement information. To our knowledge, this is the first study to find a significant negative relationship between a fish's ROM and its detection frequency, in addition to confirming the linear loss of detection frequency with increasing distance of the fish away from a monitor. The test fish was never closer than $17 \mathrm{~m}$ or further than $165 \mathrm{~m}$ away from any given monitor during its 4 d tracking period, so the linear relationship may change if the fish is closer or further from a given monitor. The phenomenon causing the reduction of detections with increasing ROM is still unclear. It is likely that the increase in ROM of this benthic-natured species causes an increase in signal occlusion arising from traveling in and out of rugose habitats. Although the test fish provided valuable information on the performance of the acoustic receivers based on the behavior of the fish, this information was only used to provide confidence in the detection frequencies of fish acoustically monitored in this study. We do not intend that this technique should replace a full study of a species fine-scale home range using manual telemetry. Future studies should focus on expanding this technique as a way to better calibrate the effectiveness of acoustic arrays in areas with complex habitat.

\section{Site fidelity}

This study found that most (92\%) Semicossyphus pulcher exhibited long-term, consistent residence in the area of the reserve, with short-term excursions up to $1 \mathrm{~km}$ away from core areas. Transmitters appeared to vary in longevity (451 $\pm 162 \mathrm{~d}$ ); a conservative definition is that fish detected for at least $90 \%$ of the days over a $300 \mathrm{~d}$ period exhibited residency (Table 1). Topping et al. (2005) found that S. pulcher manually tracked from 48 to $144 \mathrm{~h}$ in the CMLR had small home ranges (938 to $82000 \mathrm{~m}^{2}$ ) and would return nightly to within a few meters of the same nighttime resting location within a 6 mo period. While passive monitoring lacks the resolution to determine if fish return to the same area each night, this study did show variation in general area use and shifts in nighttime location between non-overlapping monitor areas, which we observed only once in the manual tracking study.

Fish in this study did show shifts in area use, including switching core areas and nighttime areas during 1 yr monitoring. Fish No. 6 switched residency from $\mathrm{P}$ to IP 3 times, while Fish No. 11 gradually shifted its core area from $3 \mathrm{C}$ to Pump to the reserve boundary during the last 3 mo of detection. Using passive monitoring, we were able to document switching of both nighttime and daytime areas. This shifting of core areas was detected only once by short-term manual telemetry over $6 \mathrm{mo}$, indicating that passive monitoring methods may be essential in determining longerterm fidelity to home ranges (Topping et al. 2005).

Although we could not statistically determine sexrelated differences in site fidelity, it warrants noting that the 3 fish (Nos. 6, 11, 16) that exhibited core area shifting and showed the least site fidelity were all 
females. Topping et al. (2005) also reported that the only fish to change its nighttime location was a female $(28.5 \mathrm{~cm} \mathrm{SL})$; the shift occurred 5 mo after the initial tracking. In a monitoring study of Tautoga onitis, another temperate labrid, Arendt et al. (2001b) (examining site use in natural and man-made structures) reported that the only 2 fish that left one of the artificial reefs were females. It is not completely clear why females appear to have lower site fidelity, but it could be related to their smaller size. Warner (1975) found that Semicossyphus pulcher undergoing sexual transition from female to male at Catalina Island ranged between 24 and $32 \mathrm{~cm}$ SL. Therefore, some females may search for new areas in which to reside during their transition to males or, since there is a dominance hierarchy in this species (Cowen 1990, Adreani et al. 2004), smaller fish may get pushed out of optimal habitat.

\section{Seasonal movement patterns}

Semicossyphus pulcher expanded their maximum ranges between December 2001 and March 2002. Of 13 fish, 10 significantly increased their range by $>300 \mathrm{~m}$ in January 2002, and at least 4 of these increased their overall range to over $1 \mathrm{~km}$. The 2 main peaks of this range expansion were 21 January 2002 and 8 March 2002, which appeared to correlate with 2 separate periods of an increase in mean water column temperature (Fig. 4). Although the temperatures slowly rose over approximately $20 \mathrm{~d}$, reaching maximums on 21 January 2002 and 8 March 2002, they were followed by relatively rapid declines. While these short-term temperature increases probably had a positive effect on the fish's activity (i.e. ROM) (Olla et al. 1974, Claireaux et al. 1995), it does not completely explain why, during this period, fish increased their range to a greater extent than during previous months when temperatures were $\geq 15^{\circ} \mathrm{C}$.

As mentioned above, female fish (Nos. 6, 11, 16) exhibited a shift in core area between January and March 2002. Based on gonad development and gonadal somatic indices (GSI), Warner (1975) determined that Semicossyphus pulcher spawn at Catalina Island from late June to September. GSI values begin to increase in April, reaching a maximum in July, and return to a minimum in October. Warner (1975) also noted that transitional individuals were only found from October to March. As a protogynous hermaphrodite, the initiation of sex change of $S$. pulcher from female to male is linked to environmental and social factors (Warner 1975, Cowen 1990). The period of range expansion exhibited in our study corresponds to the period when transitional individuals are predicted to change prior to the onset of annual gonadal development. Therefore, it is possible that these fish are expanding their range to increase the occurrence of social interactions, thereby determining their schedule of change or their location of future spawning activity.

Over the range of water temperatures experienced by these fish during the entire year $\left(12.5\right.$ to $\left.18.5^{\circ} \mathrm{C}\right)$, overall activity significantly increased as mean water column temperature increased, as predicted by the decrease in detection frequencies of each fish (i.e. increased ROM). The increase in activity of Semicossyphus pulcher with increasing temperature (within their thermal limits) corroborates the results of other studies (e.g. Olla et al. 1974, Claireaux et al. 1995, Briggs \& Post 1997, Clarke \& Johnston 1999). In fact, Claireaux et al. (1995) found that Gadus morhua exhibited a 2-fold increase in swimming activity $(9.4$ to $17.9 \mathrm{~km}$ $\mathrm{d}^{-1}$ ) with only a $2^{\circ} \mathrm{C}$ change in water temperature. Olla et al. (1974) also found that activity of Tautoga onitis was positively related to water temperature, with fish remaining normally active down to temperatures of $9^{\circ} \mathrm{C}$, and fish found in a quiescent state at temperatures of 2 to $5^{\circ} \mathrm{C}$. In $T$. onitis, the onset of spawning has been attributed to water temperature $\left(\sim 11^{\circ} \mathrm{C}\right)$, with spawning temporally staggered by latitude as incremental increases in water temperature occur along the NW Atlantic coast (Hostetter \& Munroe 1993, White et al. 2003). It is not known if $S$. pulcher follows this same regional spawning pattern, but we found a sharp change in detection frequency of fish from April/May (onset of gonadal development) to June/July (expected spawning period) as the mean water column temperature reached $16^{\circ} \mathrm{C}$ (Fig. 5a), possibly signaling a significant change in behavior associated with spawning.

Mean daily detection frequencies for Cove fish reached a maximum from April to May (315 detections $\mathrm{d}^{-1}$ at 13 to $16^{\circ} \mathrm{C}$ ) and were lowest from July to September (83 detections $\mathrm{d}^{-1}$ at 16 to $18^{\circ} \mathrm{C}$ ). These maximum detection frequencies are probably the result of a decrease in activity (ROM) and a reduced movement away from core areas, and occurred during the predicted start of gonadal development. Koch \& Wieser (1983) found that the roach Rutilus rutilus exhibited a reduction in swimming activity during seasonal gonadal development that completely compensated for the cost of the production of gonadal tissue. Semicossyphus pulcher may also limit their rate of movement in order to reduce energy expenditure, allocating more into gonadal growth (Koch \& Wieser 1983, Baras 1995) and/or to remain within spawning territories (Adreani et al. 2004).

The seasonal detection patterns for Semicossyphus pulcher in the Cove were similar to those of acoustically monitored tautog by Arendt et al. (2001a), who recorded minimum daily detections from January to 
March $\left(5\right.$ to $\left.8^{\circ} \mathrm{C}\right)$, maximum detections from April to May (as the water temperature increased from 10 to $20^{\circ} \mathrm{C}$ ), and reduced detections from June to September $\left(20\right.$ to $\left.27.5^{\circ} \mathrm{C}\right)$. However, they believed that lower detection frequencies were due to lower activity when fish were resting in shelters (rock crevices, etc.) at low and high temperatures (thermal min./max.), but actual activity patterns were based on anecdotal observations in other locations. Nevertheless, S. pulcher manually tracked within each season to exhibited typical diurnal behavior, with fish leaving their nighttime rest areas each day to forage at locations up to $800 \mathrm{~m}$ away and spending little time resting within rock crevices or holes (Topping et al. 2005). Therefore, we believe that $S$. pulcher's daytime use of structures to rest was minimal, and was not the primary cause of periods of reduced detections throughout the year.

\section{Conclusions and reserve management implications}

Most fish ( $\mathrm{n}=13$ ) were detected daily by at least 1 monitor in the array, suggesting that minimum coverage was achieved for a residence study of the CMLR's Semicossyphus pulcher population. During the December 2001 to March 2002 range expansion recorded during this study, at least 4 fish expanded their range throughout the length of the reserve $(1 \mathrm{~km})$, increasing the possibility of fish crossing the reserve boundary for short periods during these months (Topping et al. 2005). Fish in the CMLR that have core areas within $300 \mathrm{~m}$ of the reserve boundary would be expected to cross the boundary at some point during the year, considering that we found that most fish regularly traveled up to $600 \mathrm{~m}$ during the study. Depending on the number of fish that fisheries managers desire to protect, this boundary could be adjusted accordingly. Kramer \& Chapman (1999) suggested that maximizing the area:boundary length ratio would effectively reduce spillover. In a previous study, we found that the Cove had a 4.5 times greater area:boundary length ratio (188:1) than the Outside Wall (42:1) and had the lowest percentage of fish crossing the boundary (Topping et al. 2005). In the present study, none of the fish that were originally caught in the Cove ever completely shifted their core area out of the reserve. This study provides a foundation for estimating the overall effectiveness of reserves in managing $S$. pulcher stocks based on residency and seasonal movements. With the use of reserves increasing globally, passive acoustic monitoring systems should be used to determine the effectiveness of reserves in protecting other target species.
Acknowledgements. Special thanks to Y. Papastamatiou and D. Cartamil for their extensive work in this study. In addition, we thank A. Beck, C. Snellen, C. Jackson, E. Jarvis, G. Hoisington, J. Vaudo, K. Anthony, K. Goldman, L. Galima, S. Sharfi, S. Mutz, and S. Neumann for the many hours of tracking and diving. Support for this work was supplied by the National Fish and Wildlife Foundation Grant project \#2000-0117-000 and California Sea Grant College Program NOAA NA06RG042 2002-03, project \# R/F-192. This work was done under California State University Long Beach Animal Care Protocol \#186, which complies with the current laws of the country in which the experiments were performed. Additional scholarship awards that supported this project included both the SCTC Marine Biology Educational Foundation award and the California State University Long Beach Loomis Award. We greatly thank the Wrigley Marine Science Center for the use of their facilities, with the working support of K. A. Miller, C. Yonker, N. Murphy, and D. Smith.

\section{LITERATURE CITED}

Adreani MS, Erisman BE, Warner RR (2004) Observations of courtship behavior and spawning in the California sheephead, Semicossyphus pulcher (Pisces: Labridae). Environ Biol Fish 71:13-19

Arendt MD, Lucy JA, Evans DA (2001a) Diel and seasonal activity patterns of adult tautog, Tautoga onitis, in lower Chesapeake Bay, inferred from ultrasonic telemetry. Environ Biol Fish 62:379-391

Arendt MD, Lucy JA, Munroe TA (2001b) Seasonal occurrence and site-utilization patterns of adult tautog, Tautoga onitis (Labridae), at manmade and natural structures in lower Chesapeake Bay. Fish Bull (Wash DC) 99: 519-527

Atchley WR, Gaskins CT, Anderson D (1976) Statistical properties of ratios I. Empirical results. Syst Zool 25: 137-148

Baras E (1995) Seasonal activities of Barbus barbus: effect of temperature on time-budgeting. J Fish Biol 46:806-818

Barrows E (1996) Animal behavior desk reference, 2nd edn. CRC Press, Boca Raton, FL

Bolden SK (2000) Long-distance movement of a Nassau grouper (Epinephelus striatus) to a spawning aggregation in the central Bahamas. Fish Bull (Wash DC) 98:642-645

Bradbury C, Green JM, Bruce-Lockhart M (1995) Home ranges of female cunner, Tautogolabrus adspersus (Labridae), as determined by ultrasonic telemetry. Can J Zool 73:1268-1279

Briggs CT, Post JR (1997) In situ activity metabolism of rainbow trout (Oncorhynchus mykiss): estimates obtained from telemetry of axial muscle electromyograms. Can J Fish Aquat Sci 54:859-866

Claireaux G, Webber DM, Kerr SR, Boutilier RG (1995) Physiology and behaviour of free-swimming Atlantic cod (Gadus morhua) facing fluctuating temperature conditions. J Exp Biol 198:49-60

Clarke A, Johnston NM (1999) Scaling of metabolic rate with body mass and temperature in teleost fish. J Anim Ecol 68: 893-905

Coleman FC, Koenig CC, Collins LA (1996) Reproductive styles of shallow water groupers (Pisces: Serranidae) in the eastern Gulf of Mexico and the consequences of fishing spawning aggregations. Environ Biol Fish 47:129-141

Cowen RK (1986) Site-specific differences in the feeding ecology of the California sheephead, Semicossyphus pulcher (Labridae). Environ Biol Fish 16:193-203 
Cowen RK (1990) Sex change and life history patterns of the labrid, Semicossyphus pulcher, across an environmental gradient. Copeia 3:787-795

Heupel MR, Simpfendorfer CA, Hueter RE (2004) Estimation of shark home ranges using passive monitoring techniques. Environ Biol Fish 71:135-142

Heupel MR, Semmens JM, Hobday AJ (2006) Automated acoustic tracking of aquatic animals: scales, design and deployment of listening station arrays. Mar Freshw Res 57: $1-13$

Hobson ES, Chess JR (1986) Relationships among fishes and their prey in a nearshore sand community off southern California. Environ Biol Fish 17:201-226

Hooge PN, Eichenlaub WM, Solomon EK (1999) The animal movement program. US Geographical Survey, Alaska Biological Science Center, Anchorage, AK

Hooge PN, Eichenlaub WM, Solomon EK (2001) Using GIS to analyze animal movements in the marine environment. In: Kruse GH, Bez N, Booth A, Dorn MW and 6 others (eds) Spatial processes and management of marine populations. University of Alaska Sea Grant College, Fairbanks, AK, p $37-51$

Hostetter EB, Munroe TA (1993) Age, growth, and reproduction of tautog Tautoga onitis (Labridae: Perciformes) from coastal waters of Virginia. Fish Bull (Wash DC) 91:45-64

Jakob EM, Marshall SD, Uetz GW (1996) Estimating fitness: a comparison of body condition indices. Oikos 77:61-67

Johnson DR, Funicelli NA, Bohnsack JA (1999) Effectiveness of an existing estuarine no-take fish sanctuary within the Kennedy Space Center, Florida. N Am J Fish Manag 19: 436-453

Johnson TD, Barnett AM, Demartini EE, Craft LL, Ambrose RF, Purcell LJ (1994) Fish production and habitat utilization on a southern California artificial reef. Bull Mar Sci 55:709-723

Koch F, Wieser W (1983) Partitioning of energy in fish: can reduction of swimming activity compensate for the cost of production? J Exp Biol 107:141-146

Kramer D, Chapman M (1999) Implications of fish home range size and relocation for marine reserve function. Environ Biol Fish 55:65-79

Lowe CG, Topping DT, Cartamil DP, Papastamatiou YP (2003) Movement patterns, home range and habitat utilization of adult kelp bass Paralabrax clathratus in a temperate notake marine reserve. Mar Ecol Prog Ser 256:205-216

McClanahan TR, Mangi S (2000) Spillover of exploitable fishes from a marine park and its effect on the adjacent fishery. Ecol Appl 10:1792-1805

Meyer CG, Holland KN, Wetherbee BM, Lowe CG (2001) Movement pattern, habitat utilization, home range size and site fidelity of whitesaddle goatfish (Parupeneus porphyreus). Environ Biol Fish 59:235-242

Editorial responsibility: Howard Browman (Associate Editorin-Chief), Storebø, Norway
O'Dor RK, Aitken JP, Babcock RC, Bolden SK, Zeller DC, Jackson GD (2002) Electronic tagging and tracking in marine fisheries. In: Sibert J, Nielsen J (eds) Using radioacoustic positioning and telemetry (RAPT) to define and assess marine protected areas (MPAs). Kluwer Academic Press, Dordrecht, p 147-166

Olla BL, Bejda AJ, Martin AD (1974) Daily activity, movements, feeding, and seasonal occurrence in the tautog, Tautogo onitis. Fish Bull (Wash DC) 72:27-35

Parsons DM, Babcock RC, Hankin RKS, Willis TJ, Aitken JP, O'Dor RK, Jackson GD (2003) Snapper Pagrus auratus (Sparidae) home range dynamics: acoustic tagging studies in a marine reserve. Mar Ecol Prog Ser 262:253-265

Roberts CM, Bohnsack JA, Gell F, Hawkins JP, Goodridge R (2001) Effects of marine reserves on adjacent fisheries. Science 294:1920-1923

Sheaves MJ, Molony BW, Tobin AJ (1999) Spawning migrations and local movements of a tropical sparid fish. Mar Biol 133:123-128

Simpfendorfer CA, Heupel MR, Hueter RE (2002) Estimation of short-term centers of activity from an array of omnidirectional hydrophones and its use in studying animal movements. Can J Fish Aquat Sci 59:23-32

Starr RM, Heine JN, Johnson KA (2000) Techniques for tagging and tracking deepwater rockfishes. N Am J Fish Manag 20:597-609

Starr RM, Heine JN, Felton JM, Cailliet GM (2002) Movements of bocaccio (Sebastes paucispinis) and greenspotted (Sebastes chlorostictus) rockfishes in a Monterey submarine Canyon: implications for the design of marine reserves. Fish Bull (Wash DC) 100:324-337

Stephens JS (2002) California Sheephead. In: Larson EJ (ed) California's marine living resources: a status report. California Department of Fish and Game, Sacramento, CA, p 155-156

Summerfelt RC, Smith LS (1990) Anesthesia, surgery, and related techniques. In: Schreck CB, Moyle PB (eds) Methods for fishery biology. American Fisheries Society, Bethesda, MD, p 213-272

Szedlmayer ST, Schroepfer RL (2005) Long-term residence of red snapper on artificial reefs in the northeastern Gulf of Mexico. Trans Am Fish Soc 134:315-325

Topping DT, Lowe CG, Caselle JE (2005) Home range and habitat utilization of adult California sheephead, Semicossyphus pulcher (Labridae), in a temperate no-take marine reserve. Mar Biol 147:301-311

Warner RR (1975) The reproductive biology of the protogynous hermaphrodite Pimelometopon pulchrum (Pisces: Labridae). Fish Bull (Wash DC) 73:262-283

White GW, Munroe TA, Herbert MA (2003) Reproductive seasonality, fecundity, and spawning frequency of tautog (Tautoga onitis) in the lower Chesapeake Bay and coastal waters of Virginia. Fish Bull (Wash DC) 101:424-442

Submitted: November 10, 2005; Accepted: April 1, 2006

Proofs received from author(s): October 27, 2006 